This item was submitted to Loughborough's Research Repository by the author.

Items in Figshare are protected by copyright, with all rights reserved, unless otherwise indicated.

Working time and cigarette smoking: evidence from Australia and the United Kingdom

PLEASE CITE THE PUBLISHED VERSION

http://dx.doi.org/10.1016/j.socscimed.2014.04.031

PUBLISHER

(C) Elsevier

VERSION

AM (Accepted Manuscript)

LICENCE

CC BY-NC-ND 4.0

REPOSITORY RECORD

Angrave, Dave, Andy Charlwood, and Mark Wooden. 2014. "Working Time and Cigarette Smoking: Evidence from Australia and the United Kingdom". Loughborough University. https://hdl.handle.net/2134/14690. 
This item was submitted to Loughborough's Institutional Repository (https://dspace.lboro.ac.uk/) by the author and is made available under the following Creative Commons Licence conditions.

\section{creative
commons}

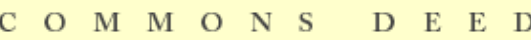

Attribution-NonCommercial-NoDerivs 2.5

You are free:

- to copy, distribute, display, and perform the work

Under the following conditions:

Attribution. You must attribute the work in the manner specified b the author or licensor.

Noncommercial. You may not use this work for commercial purposes.

No Derivative Works. You may not alter, transform, or build upon this work.

- For any reuse or distribution, you must make clear to others the license terms of this work.

- Any of these conditions can be waived if you get permission from the copyright holder.

Your fair use and other rights are in no way affected by the above.

This is a human-readable summary of the Leqal Code (the full license).

\section{Disclaimer 만}

For the full text of this licence, please go to: http://creativecommons.org/licenses/by-nc-nd/2.5/ 


\title{
Working time and cigarette smoking: evidence from Australia and the United Kingdom
}

\section{David Angrave*, Andy Charlwood** and Mark Wooden***}

Key words: working time; smoking; smoking intensity; Australia; United Kingdom

* York Management School, University of York

**School of Business and Economics, Loughborough University (corresponding author: a.charlwood@lboro.ac.uk)

***Melbourne Institute of Applied Economic and Social Research

\section{Research highlights}

Within-person analysis of the working time-smoking relationship.

Analysis based on two nationally representative panel surveys.

Longer working hours associated with reduced odds of quitting smoking.

Former smokers who work long hours more likely to relapse.

Increases in hours also associated with increased cigarette consumption.

\begin{abstract}
Cigarette smoking is a risk factor in a range of serious diseases, including cardiovascular disease, cancer, stroke and type II diabetes. Theory suggests that working long hours will increase smoking propensities among workers. Consequently there is a significant body of evidence on the relationship between working time and smoking. Results, however, are inconsistent and therefore inconclusive. This paper provides new evidence on how working time affects smoking behaviour using nationally representative panel data from Australia (from 2002 to 2011) and the United Kingdom (from 1992 to 2011). We exploit the panel design of the surveys to look at within-person changes in smoking behaviour over time as working time changes. In contrast to most previous studies, this means we control for time invariant aspects of personality and genetic inheritance that may affect both smoking propensities and choice of working hours. We find that working long hours tends to increase the chances that former smokers will relapse,
\end{abstract}


reduce the chances that smokers will quit and increase cigarette consumption among regular smokers, and that these effects tend to become more pronounced for workers who usually work very long hours (50 or more hours a week) compared to those who work moderately long hours (40-49 hours a week).

\section{Introduction}

Cigarette smoking is a risk factor in a range of serious diseases, including cardiovascular disease (Ezzati, Henley, Thun \& Lopez, 2005a), cancer (Ezzati, Henley, Thun \& Lopez, 2005b), stroke (Shinton \& Beevers, 1989) and type II diabetes (Rimm, Chan, Stampfer, Colditz, \& Willett, 1995). Consequently there is a very large body of empirical research that seeks to identify the risk factors that make smoking more likely and increase smoking intensity. One strand of this literature looks at the role of work in influencing smoking behaviour, focusing particularly on the role of working hours and psycho-social conditions at work (e.g., Lallukka et al., 2008; Macy, Chassin \& Presson, 2013). However, the evidence from this research, which is based mainly on cross-sectional analysis of specific occupations and workplaces, is inconsistent and therefore inconclusive. Our study provides new evidence on this issue by analysing nationally representative panel survey data from both Australia and the United Kingdom (UK). We exploit the panel design of the surveys to look at changes in smoking behaviour within the same individuals over time as working conditions change, allowing us to control for time-invariant individual characteristics and draw stronger inferences about causality.

Why might working conditions, and long hours of work in particular, increase the likelihood of smoking? Smokers experience smoking as a stress relieving activity (Jarvis, 2002), and if working is a stressful activity it follows that work would increase smokers' propensities to smoke. Long hours of work may act as a stressor for two reasons. First, workers tend to feel less happy, less relaxed and more anxious or stressed when at work than when taking part in most other activities (Kahneman, Krueger, Schkade, Schwarz, \& Stone, 2004; Bryson \& MacKerron, 2013). 
Second, if a job is particularly demanding, it may only be possible to meet those demands by working long hours. Therefore, long hours of work may be an indicator of other stressors.

A number of studies have attempted to identify links between working time and smoking. A systematic review of this research was conducted by van der Hulst (2003) who identified seven studies. Six of these were based on small samples from a single occupation or organisation, while the one study with a much larger sample size $(\mathrm{N}=3917)$ was of a single occupation (nurses). Only one was based on longitudinal data and within-person analysis (Steptoe et al., 1998). This study was the only one to find any relationship between long hours of work and smoking. Specifically, it found that smoking intensity increases as working hours increase. However, it was based on just 71 workers in a single department store in the UK, so the extent to which its findings can be generalised to other contexts is unclear.

Turning to research conducted since the publication of van der Hulst's review, Mizoue et al. (2006) examined the relationship between working overtime and smoking intensity in a crosssectional sample of 642 male Japanese office workers. This study identified a u-shaped relationship between smoking intensity and overtime, with those working moderate amounts of overtime smoking less than both those who worked low or high levels of overtime. Radi, Ostry and LaMontagne (2007) studied smoking status and intensity among a cross-sectional sample of 1101 Australians from the state of Victoria. They found that long working hours (50 or more per week) were associated with a higher propensity to smoke among men (but not greater smoking intensity). Lallukka et al. (2008) studied the relationship between psycho-social job stress, working overtime (defined as a usual working week of more than 40 hours) and smoking among civil servants aged 45-60 in London, Helsinki and Japan $(n=11,680)$. Their results differed between men and women and between geographical locations. Surprisingly, they found that men in Japan and Helsinki who worked overtime hours smoked less than other workers. Macy, 
Chassin and Presson (2013) investigated the effects of changes in working time on a range of health risk behaviours, including smoking among a community based sample from the American mid-west $(n=3,984)$. They found no relationship between an increase in hours worked and daily smoking activity, although they did not test specifically for the effects of changes to long-hours working.

Additionally, there are two studies of the relationship between smoking and working time based on broadly nationally representative panel data but which only utilised between-person methods. Albertsen, Hannerz, Borg and Burr (2004) studied the determinants of quitting smoking among 3606 Danish workers. They found that working long hours (41 hours or more a week) had no impact on smoking cessation. Taris et al. (2011) examined the relationship between harmful behaviours (an index based on the combined intensity of smoking and alcohol consumption) and overtime working. They found no relationship between an increase in harmful behaviour and the number of overtime hours worked among a sample of 649 full-time employees in the Netherlands. A common limitation to both studies is that the measures of working time do not differentiate effectively between moderately long working hours and very long working hours.

We are aware of only one study that has employed a large $(n=3,830)$ nationally representative sample to examine changes in within-person smoking behaviour over time (Shields, 1999). This Canadian study found that when men move from working 40 hours or less per week to more than 40 hours a week, their odds of increasing daily smoking activity doubled, while for women the odds quadrupled.

In summary, there are two important shortcomings in existing studies, at least one of which afflicts all the studies discussed above except Shields (1999). First, most use samples covering a particular occupation, workplace and/or age group. Therefore the extent to which the results can 
be generalized is limited. Second, all studies except Shields (1999) and Steptoe et al. (1998), employ methods that describe how the relationship between working time and smoking varies between subjects rather than within subjects over time. This is important, because methods based on between-subject comparisons do not account for time-invariant aspects of personality and genetic inheritance, which might partially account for both the propensity to smoke and choice of working hours. It is only by studying changes in smoking behaviour within individuals as working time changes that we can obtain estimates of the relationship between working time and smoking that are not biased by failure to account for these unobserved individual characteristics.

The study reported in this article is designed to overcome these limitations. It analyses the relationship between working time and cigarette smoking using data from two large, longrunning nationally representative panel surveys. This permits analysis of within-person changes in working time and within-person changes in both smoking status (quitting or starting smoking) and smoking intensity, so reducing the scope for results to be biased due to omitted variables. The nationally representative nature of the data also means that we can generalise to the wider populations of Australia and the UK. Finally, and in contrast to most previous research, we use detailed measures of working time that capture the difference between moderately long working hours and very long working hours. In short, we are able to offer a far more rigorous test of the hypothesis that long working hours result in the adoption of less healthy lifestyles than any previous study.

Additionally, both Australia and the UK have a similar approach to the regulation of working time, with ample scope provided for workers in both countries to work for longer than the stipulated maximum hours if they or their employers wish. Specifically, in Australia, while the National Employment Standards stipulate a 38 hour working week, they also provide for 
'reasonable additional hours' and hence voluntary overtime (paid or unpaid) is common. Similarly, while in the UK there is a notional 48 hour maximum working week, under the terms of the European working time directive employees may opt out from the requirements of the directive if they wish. The two countries also share a common language, cultural heritage and similar legal system. Therefore, the two-country comparison allows us to examine whether the results are consistent (and therefore less likely to be the result of chance) across countries with broadly similar contextual characteristics.

\section{Methods}

Data

Our data come from two stratified random household panel surveys: the Household, Income and Labour Dynamics in Australia (HILDA) Survey, and the British Household Panel Survey (BHPS). Both conduct annual interviews with all adult members (defined as 15 years or older in the HILDA Survey and 16 years or older in the BHPS) of a nationally representative sample of households. Both have similar automatic sample replenishment rules; when a survey participant leaves a household an attempt is made to track them into their new household, which then joins the survey. New persons who join a sample household, including children, are added to the samples. Thus, with the exception of new immigrants who arrive in the country after the studies commenced, the surveys should remain broadly representative of the populations from which they are drawn.

Described in more detail in Watson and Wooden (2012), the HILDA Survey began in 2001. An initial responding sample of 7682 households was achieved ( $66 \%$ of households approached). Annual re-interview rates (the proportion of respondents from one wave who are successfully interviewed the next, after excluding deaths and moves abroad) are reasonably high, rising from $87 \%$ in wave 2 to over $94 \%$ by wave 5 . In the following survey waves (2006 to 2011) the re- 
interview rate has been relatively stable, averaging almost $96 \%$. Data are collected via both interviewer-administered and self-administered instruments. The majority of self-administered questionnaires (70\% on average) are collected by interviewers. If not completed by the time of collection, respondents are asked to return them by mail. As a result, there is additional nonresponse associated with this component of the survey; on average, about $90 \%$ of all interviewees complete and return the self-completion questionnaire.

The BHPS began in 1991 with a sample of residents of 5538 British households (see Taylor, Brice, Buck, \& Prentice-Lane, 2010). In addition to households that joined the survey through the automatic replenishment rules described above, a further 2887 households from Scotland and Wales were added to the survey in 1999. The scope of the survey was extended to cover all of the UK in 2001, when 1979 households from Northern Ireland were added. The BHPS was replaced by the UK Household Longitudinal Study (UKHLS) in 2009, with the BHPS sample continuing to be followed and interviewed as part of the new larger survey. At wave one $74 \%$ of all in-scope selected households agreed to an interview. The annual re-interview rates for the main sample, however, followed a remarkably similar path to those documented for the HILDA Survey (see Watson \& Wooden, 2010: 328), reaching 94\% in wave 5 and averaging around 95\% for most of the years that followed. The notable exception is wave 19, when the BHPS was subsumed within the new UKHLS; only $79 \%$ of respondents who gave a full interview in wave 18 (and who were issued to field in wave 19) also gave a full interview at wave 19 (Lynn, Burton, Kaminska, Knies, \& Nandi, 2012).

\section{Measures of smoking}

The BHPS asks respondents "Do you smoke?" Smokers are then asked "approximately how many cigarettes a day do you normally smoke?" These questions are asked in face-to-face interviews. By contrast, the HILDA Survey asks questions about smoking in its self-completion 
questionnaire. The wording of the questions is also different, with the HILDA question reading "do you smoke cigarettes or other tobacco products?" with five response categories provided (no, never; no longer; yes; daily; yes, weekly but not every day; yes, regularly but not every week), which we combined to produce a binary variable indicating an active smoker (where the response was any of the three 'yes' response categories). In all waves except wave 1, smokers are then asked "how many cigarettes do you usually smoke each week?". To provide comparability between surveys, weekly cigarette consumption in the HILDA Survey was divided by 7 to derive a daily cigarette consumption figure.

Because we are interested in how changes in working time relate to changes in smoking, we created two binary dependent variables to capture changes in smoking status. The first, "stopped smoking", has a value of one when a respondent reports that they do not smoke in the current wave of the survey, but had reported smoking in the previous wave, and a value of zero when a respondent reports smoking in both the previous and current wave of the survey (respondents who did not smoke in the previous wave were discarded from the analysis). The second, "started smoking", has a value of one when a respondent reports that they smoke in the current wave, but not in the previous wave. It has a value of zero when a respondent was a non-smoker in both waves (respondents who smoked in both waves were discarded from the analysis). Both surveys have also collected data on previous smoking history, which we can use to determine whether respondents who start smoking between waves are starting smoking for the first time or relapsing having previously quit smoking. Preliminary analysis indicated that of those respondents we observed starting, just $4.4 \%$ of our UK sample and $5.4 \%$ of our Australian sample had no previous history of smoking. Therefore, keep in mind that our start smoking variable is typically an indicator of relapsing by smokers who had previously quit. 
To capture changes in the number of cigarettes smoked (smoking intensity), we created a continuous dependent variable, which subtracted the weekly cigarettes smoked response in the previous wave of the survey from the number smoked in the current wave. Note also that because no information on the number of cigarettes smoked was collected in wave 1 of the HILDA Survey, our analysis of the number of cigarettes smoked for our Australian sample begins with wave 3 .

\section{Working time}

We created comparable variables that measure usual weekly working hours (including any unpaid overtime) in the respondents' main job. Intuitively we might expect the relationship between working time and health risk behaviours to be non-linear; i.e., risky behaviours will be more likely for employees who work very long hours (50 hours or more per week) rather than moderately long hours. Therefore we created a categorical variable with the following values: fewer than 20 hours; 20 to 34 hours; 35 to 40 hours; 41 to 49 hours; 50 to 59 hours; and 60 or more hours per week. We report the proportions of our samples who took up or quit smoking, along with the mean numbers of cigarettes smoked each day by active smokers and the proportions of respondents in each hours category in Table 1. Binary variables based on this categorical variable are then used in our analysis, with 35 to 40 hours as the omitted reference category.

\section{Covariates}

The presence of other household members during the interview is a possible source of bias in self-reports of smoking (particularly for the BHPS where smoking data were collected through interview). Therefore we included a variable indicating the presence of others during the interview. Additionally, we included measures of whether or not another household member smoked, disability, whether the respondent was married or cohabiting, whether the respondent 
lived with a child or children aged under 5 , whether the respondent lived with a child or children aged 5 to 18, broad occupational group (using the International Standard Classification of Occupations 88), dummy variables for survey wave, and the log of real equivalised household income and its square (meaning that any cases with non-positive household income were omitted). Nominal income values were converted into constant price equivalents by using the relevant official consumer price index (excluding house prices and financial services in order to ensure comparability between the measures used for Australia and the UK) available in each country, while we adjust for household size and composition using the OECD modified equivalence scale (Hagenaars, de Vos, \& Zaidi, 1994).

\section{Sample size and representativeness}

The initial design of our survey means that the samples we are analysing should be broadly representative of the working population of the UK and Australia. Panel attrition may introduce bias, but as discussed later, we explicitly test for this and could find no evidence to suggest attrition was a source of bias.

Non-response to questions on smoking and other covariates may introduce another source of bias. Six percent of the BHPS sample and $10 \%$ of the HILDA Survey did not respond to the questions on smoking. A further 14\% in the BHPS and $6 \%$ of the HILDA survey did not respond to questions about one or more of the covariates. If we make the standard assumption that item non-response is essentially random, then results will remain broadly representative of the wider populations.

After non-response is accounted for, we have 20,577 individuals providing 109,284 usable observations from the UK and 14,479 individuals providing 75,522 usable observations from Australia. The actual numbers of observations available for inclusion in the regression models 
reported in Tables 2 to 4 is considerably less than this, because the fixed effects method means we are examining within-person changes and so observations where the covariates remain constant over time are discarded (we provide descriptive statistics for the samples used in each regression model in an online appendix).

Key descriptive statistics for the incidence of smoking (reported below) are consistent with official statistics from British (Office for National Statistics, 2013) and Australian (Australian Bureau of Statistics, 2013) national statistics agencies.

\section{Statistical methods}

At the centre of this analysis is the estimation of fixed effects models explaining both changes in smoking status (taking up smoking or quitting smoking) and in smoking intensity (among respondents who were active smokers in two consecutive waves of the survey). These fixed effects estimators examine within-person changes in our outcome variables and in working time while controlling for changes in other covariates, so effectively controlling for all other timeinvariant characteristics (including time-invariant aspects of personality and genetic inheritance) that may affect smoking propensities. An alternative econometric approach would have been to combine within- and between-person effects through the estimation of random effects models. For random effects to be appropriate, we must assume that the individual specific effects are uncorrelated with the independent variables included in the model. We believe this to be an unrealistic assumption. This belief was reinforced by the results of Hausman tests, which suggested that the fixed effects specification was the more efficient, and therefore the most appropriate method to use (Hausman, 1978).

Since the change in smoking status outcomes are binary variables, we use the conditional fixed effects logistic regression model (Chamberlain, 1980). Results are reported in the form of odds 
ratios. In contrast, the number of cigarettes smoked per day is more suited to estimation using a count data model, the most common example of which is the Poisson model. We thus estimated a fixed effects Poisson model (see Cameron \& Trivedi, 1998) to analyse this outcome. A control for the number of cigarettes smoked in the previous wave was included in this analysis to control for state dependence. All models were estimated using Stata 13 software. For all specifications, we estimated separate models for men and women.

\section{Results}

\section{Descriptive statistics}

Table 1 summarises the smoking propensities among our two samples, detailing the combined incidences of smoking propensities across the entirety of each sample's date range. As shown, the incidence of smoking is somewhat higher within the British sample than the Australian sample, and in both samples men are more likely to smoke than women. In our British sample $10 \%$ of smokers quit smoking during the period we observed them (18 years), compared to around $14 \%$ of smokers in the Australian sample over a shorter period (10 years). Much smaller proportions of the samples began smoking (typically relapsing having previously quit) during the survey periods.

Table 1 also presents data on the distribution of usual hours worked each week. Only around one third of men in both samples work a 'standard working week' of between 35 and 40 hours, with a sizable minority working fewer hours (11\% of the British male sample and $17 \%$ of the Australian sample), and many more working much longer hours. Indeed, 27\% of British men and $30 \%$ of Australian men report usually working 50 or more hours a week. Women in both countries are more likely to work part-time (i.e., fewer than 35 hours a week); 47\% of British women and $55 \%$ of Australian women work part-time. Women are also far less likely than men 
to work 50 or more hours a week; $7 \%$ of British women and $10 \%$ of Australian women usually worked 50 hours or more.

\section{Multivariate models}

Table 2 reports the results of our fixed effects logit models of the determinants of starting smoking. It can be seen that in both countries, the likelihood of a person who works very few hours each week (less than 20) taking up smoking relative to a person working a more conventional 35 to 40 hour week is very low (with odds ratios of under 0.5). Conversely, persons who report usually working long work weeks have very high odds ratios. In the UK sample, the higher odds ratio for taking up smoking (again) is only statistically significant for people working extremely long work hours (60 or more). In contrast, in Australia the relationship between long hours of work and starting smoking is both larger and becomes statistically significant at a lower hours threshold. When we split the results by gender, the smaller sample sizes decrease the precision of the estimates and as a result the higher odds ratios of starting smoking among persons working very long work weeks (60 or more hours) are no longer statistically significant in the UK samples. The estimated effects in the Australian samples, however, continue to be both larger than in the UK samples, and statistically significant. The much lower odds ratios for starting smoking among persons working fewer than 20 hours each also remain statistically significant among men and women in Australia and women (but not men) in the UK.

Table 3 reports an equivalent analysis for the determinants of the more frequent event, quitting smoking. In both samples, those who work more than 50 hours a week are significantly less likely to quit smoking, and this result holds when we analyse men and women separately in the UK. Within the Australian male sample the results are consistent with the hypothesis that 
overtime working is an obstacle to quitting smoking, but in this case the estimated odds ratios do not decline much within the numbers of weekly hours worked in excess of 40 , and indeed at very long hours (60 or more a week) the estimates are imprecise and hence statistically insignificant. Among Australian women on the other hand, we could find no evidence of significant associations between hours worked and the likelihood (or odds) of smoking cessation.

We now turn now to our results from the analysis of the determinants of smoking intensity, measured by the number of cigarettes smoked per day among regular smokers (reported in Table 4). Results are reported in the form of exponentiated coefficients. To calculate a numerical estimate of the change in the number of cigarettes smoked per day associated with a change in hours worked category, we multiply a baseline number of cigarettes smoked per day by the exponentiated coefficient. Here results suggest that cigarette consumption is greater in both the UK and Australian samples when respondents work more than 40 hours a week. In the UK the size of this effect increases as hours increase. In contrast, in Australia the number of cigarettes smoked does not rise further until hours increase to 50 hours a week and beyond. When we split the results by gender, we find that the higher levels of cigarette consumption among workers working in excess of 40 hours a week is characteristic of both men and women in the UK, but is largely confined to women in Australia. We also find that women in the UK smoke more when they work less than 20 hours a week.

\section{Sensitivity analysis: Missing values, panel attrition and omitted variables}

To test whether our results were affected by bias arising from non-random panel attrition we followed the procedure set out by Verbeek and Nijman (1992) and Wooden and Li (2014) and estimated additional models with a control for whether a respondent participated in the next wave of the survey. The estimates of this attrition control were insignificant. We also conducted additional analyses to test whether key results were sensitive to changes in model specification 
that had the effect of increasing sample size (by removing covariates with large numbers of missing values) or to weighting our results (so that analyses was based on smaller, balanced panels with weights to correct for non-response). We also investigated whether our UK results were sensitive to the length of the time period covered by the data (by restricting the sample to only cover the same years as available for the Australian analysis) and to changes over time in the population coverage of the survey (by excluding cases from Northern Ireland). Finally, for a subset of the Australia sample (waves 5 to 11), we were able to include additional controls for aspects of psycho-social job strain. None of these changes to model specification had a significant effect on our key results. We also investigated whether the effects of long hours on smoking were conditional on working hours preferences (i.e., were relationships different depending on whether a respondent's actual and preferred working hours were aligned?). They were not. Finally, we tested whether results varied across the income gradient, but small sample sizes meant that we were unable to fit models to the data for all income quartiles.

\section{Discussion}

\section{Main findings}

The key findings of this study are fourfold. First, former smokers are more likely to relapse when they work long hours (more than 50 hours a week in Australia, and more than 60 hours in the UK) and less likely to relapse if they work less than 20 hours a week. This is the case in both the UK and Australia. Second, respondents in both countries are considerably less likely to quit smoking if they work long hours. Third, there is a pronounced relationship between working long hours and increased cigarette consumption among the UK sample and a weaker relationship between working 40 to 59 hours a week and increased cigarette consumption in Australia, although the relationship is greater for women than for men. Fourth, the magnitude of the relationship between long working hours and smoking tends to be greater for women than 
for men. Overall, we find considerable evidence that long working hours make smoking more likely and some evidence that long working hours result in increased cigarette consumption. Note also that the results are remarkably similar for both countries. This consistency strengthens the likelihood that we are observing a real relationship rather than results that arise through chance.

How might the finding that the magnitude of the relationship between long working hours and smoking is greater for women than for men be interpreted and explained? We are cautious about inferring too much from these gender differences given when we split the samples by gender the numbers of observations becomes quite small, with the result that the estimates become less precise. We therefore need to wait until the analysis can be replicated on a larger data-set, so allowing for more precise estimates, before coming to any firm conclusions about the nature and potential causes of these differences. Provisionally though, we note that this is the result we would expect if women experience long hours working as a more stressful activity than men. Other evidence suggests that this might be the case. For example, Wooden et al. (2009) and Angrave and Charlwood (2013) found a negative relationship between long hours working, conditional on hours preferences, and subjective well-being, and that this negative relationship is greater for women than for men.

\section{Comparisons with previous studies}

In the introduction, we identified 14 previous studies into long working hours and smoking. Eleven of these ( 6 of the 7 studies summarised by van der Hulst, 2003; Albertsen et al., 2004; Mizoue et al., 2006; Lallukka et al., 2008; Taris et al., 2011; Macy et al., 2013) found no clear relationship between long working hours and smoking behaviour. All of these studies were based on between-person analysis. The three studies (Steptoe et al., 1998; Shields, 1999; Radi et al., 
2007) which found a relationship between working time and smoking appeared as outliers, with the preponderance of evidence suggesting that long working hours did not cause increased propensities to smoke.

In the light of our evidence, it appears that there is a link between long working hours and smoking, but the relationship can be obscured by correlations between unobserved time invariant individual characteristics, smoking and working time. This interpretation is strengthened by the fact that, although differences in the measurement of smoking and working time mean results are not directly comparable, the broad thrust of our results is in line with the findings of the only other study based on within-person analysis of broadly nationally representative panel data: Shields' (1999) study of Canada.

\section{Strengths and limitations}

The key strength of our study is its use of nationally representative panel data, which given the absence of any strong biases arising from either panel attrition (which we explicitly tested for) or item non-response, means that we can generalise results to the wider populations of Australia and the UK. This stands in marked contrast to almost all previous studies in this area. Panel data also allows us to focus on within-person changes in smoking as working hours change, so controlling for unobserved time-invariant individual characteristics. This is critical; failure to control for time-invariant individual characteristics will bias results if there is a correlation between observed covariates and these unobserved individual fixed effects.

Against these strengths must be set four limitations. First, the relatively small numbers of changes in smoking status, particularly starting smoking, combined with the small number of respondents in some of the work hours categories, make it difficult to obtain precise estimates, especially when we split the samples by gender. Second, there may be other aspects of time- 
varying living and working conditions that we have been unable to control for, and so we cannot discount the possibility that our results may be affected by omitted variable bias. Third, estimates of the incidence and frequency of cigarette smoking may be biased by under-reporting and faulty re-call of the number of cigarettes smoked. The precision of our estimates might be improved if the accuracy of self-reports could be calibrated against cotinine levels, or the relationship between changing cotinine levels and changing working time could be modelled directly. For the UK, calibration of self-reports against cotinine levels will be possible in the future, with the UKHLS collecting data on biomarkers, including cotinine, as part of wave 2 of that survey. If the collection of bio-markers were to be repeated in a future wave, it would also be possible to examine within-person changes in cotinine as working hours changed. Fourth, all studies, including this one, which show a relationship between smoking and long hours of work are from Anglophone nations. It is therefore unclear whether our results apply to countries with different institutional frameworks and cultures. This is an area for further research.

\section{Conclusions}

This study has answered the call of Lallukka et al. (2008: 1695) for longitudinal studies of the relationship between working conditions and health risk behaviours, specifically smoking. Our results demonstrate the importance of analysis based on longitudinal data, with our findings differing significantly from most of the between-person studies that dominate this literature. We found that there are significant and sizable relationships between within-person changes in smoking behaviours and within-person changes in working time in Australia and the UK. We now have evidence that changes in working time are associated with changes in smoking behaviour in three countries: Australia, the UK and the evidence from Canada provided by Shields (1999). However, it does not follow that the relationships observed in Australia, Canada and the UK will be observed in other countries with different patterns of employment, systems of labour market regulation and national and work cultures. Further advances in this area will 
depend on broadening the number of countries and contexts from which future longitudinal studies are drawn. Larger panel data sets (e.g., the UKHLS) that allow more disaggregated analyses, thus permitting better identification of the circumstances under which changes in working conditions most affect health behaviours like smoking, are also needed. Finally, our results imply considerable health costs as result of long working hours. Consequently, more extensive regulation of working time may have the effect of improving public health by reducing smoking, while dilution of working time regulation may lead to deteriorating public health.

\section{References}

Angrave, D. \& Charlwood, A. (2013). How does working time affect subjective well-being? British Evidence. Paper presented at Understanding Society Research Conference, University of Essex, Colchester (UK), 24 - 26 July.

Australian Bureau of Statistics [ABS] (2013). Gender Indicators, Australia (ABS cat. no. 4125.0). Canberra: Australian Bureau of Statistics. [Available online at: www.abs.gov.au]

Albertsen, K., Hannerz, H., Borg, V., \& Burr. H. (2004). Work environment and smoking cessation over a five-year period. Scandinavian Journal of Public Health, 32(3), 164-171.

Bryson, A., \& MacKerron, G. (2013). Are You Happy While You Work? (Centre for Economic Performance Discussion Paper No. 1187). London: Centre for Economic Performance, London School of Economics.

Cameron, A.C., \& Trivedi, P.K. (1998). Regression Analysis of Count Data. New York: Cambridge University Press. 
Chamberlain, G. (1980). Analysis of covariance with qualitative data. Review of Economic Studies, $47(1), 225-238$.

Ezzati, M., Henley, S.J., Thun, M.J., \& Lopez, A.D. (2005a). The role of smoking in global and regional cardiovascular mortality. Circulation, 112(4), 489-497.

Ezzati, M., Henley, S.J., Thun, M.J., \& Lopez, A.D. (2005b). The role of smoking in global and regional cancer epidemiology: current patterns and data needs. International Journal of Cancer, 116(6), 963-971.

Hagenaars, A., de Vos, K., \& Zaidi, M.A. (1994). Poverty Statistics in the Late 1980s: Research Based on Micro-data. Luxembourg: Office for Official Publications of the European Communities.

Hausman, J.A. (1978). Specification tests in econometrics. Econometrica, 46(6), 1251-1371.

Jarvis, M. (2002). Smoking and stress. In S. Stansfield, \& M. Marmot (Eds.), Stress and the Heart (pp. 150-157). London: BMJ Publishing.

Kahneman, D., Krueger, A.B., Schkade, D.A., Schwarz, N., \& Stone, A.A. (2004). A survey method for characterizing daily life experience: the day reconstruction method. Science, 306(5702), $1776-1780$

Lallukka, T., Lahelma, E., Rahkonen, O., Roos, E., Laaksonen, E., Martikainen, P., Head, J., Brunner, E., Mosdol, A., Marmot, M., Sekine, M., Nasermoaddeli, A., \& Kagamimori, S. (2008). Associations of job strain and working overtime with adverse health behaviours and obesity: 
evidence from the Whitehall II study, Helsinki health study, and the Japanese civil servants study. Social Science and Medicine, 66(8), 1681-1698.

Lynn, P., Burton, J., Kaminska, O., Knies, G., \& Nandi, A. (2012). An Initial Look at NonResponse and Attrition in Understanding Society (Understanding Society Working Paper Series No. 2012-12). Colchester, Essex: Institute for Social and Economic Research.

Macy, J., Chassin, L., \& Presson, C. (2013). Predictors of health behaviours after the economic downturn: A longitudinal study. Social Science \& Medicine 89, 8-13.

Mizoue, T., Fujino, Y., Yamato, H., Tokunaga, S., Kubo, T., \& Reijula, K. (2006). Overtime work, cigarette consumption, and addiction to cigarette among workers subject to mild smoking restrictions. Industrial Health, 44(2), 244-249.

Office for National Statistics [ONS] (2013). Smoking (General Lifestyle Survey Overview - a report on 2011 General Lifestyle Survey). [Online]. Available at: http://www.ons.gov.uk/ons/rel/ghs/general-lifestyle-survey/2011/rpt-chapter-1.html

Radi, S., Ostry, A., \& LaMontagne, A.D., (2007). Job stress and other working conditions: Relationships with smoking behaviours in a representative sample of working Australians. American Journal of Industrial Medicine, 50(8), 584-596.

Rimm, E., Chan, J., Stampfer, M.J., Colditz, G. A., \& Willett, W.C. (1995). Prospective study of cigarette smoking, alcohol use, and the risk of diabetes in men. British Medical Journal, 310(6979), $555-559$. 
Shields, M. (1999). Long working hours and health. Health Reports, 11, 33-48.

Shinton, R., \& Beevers, G. (1989). Meta-analysis of the relation between cigarette smoking and stroke. British Medical Journal, 298(6676), 789-794.

Steptoe, A., Wardle, J., Lipsey, Z., Mills, R., Oliver, G., Jarvis, M., \& Kirschbaum, C. (1998). A longitudinal analysis of work stress and variations in psychological well-being, cortisol, smoking and alcohol consumption. Annals of Behavioural Medicine, 20(2), 84-91.

Taris, T.W., Ybema, J.F., Beckers, D.G.J., Verheijden, M.W., Guerts, S.A.E., \& Kompier, M.A.J. (2011). Investigating the associations among overtime work, health behaviours, and health: a longitudinal study among full-time employees. International Journal of Behavioral Medicine, 18(4), $352-360$.

Taylor, M.F. (Ed.), with Brice J., Buck N., \& Prentice-Lane E. (2010). British Household Panel Survey User Manual, Volume A: Introduction, Technical Report and Appendices. Colchester: Institute for Social and Economic Research, University of Essex.

Van der Hulst, M. (2003). Long workhours and health. Scandinavian Journal of Work and Environmental Health, 29(3), 171-188.

Verbeek, M., \& Nijman, T. (1992). Testing for selectivity bias in panel data models. International Economic Review, 33(3), 681-703. 
Watson, N., \& Wooden, M. (2010). The HILDA Survey: progress and future developments. The Australian Economic Review, 43(3), 326-336.

Watson, N., \& Wooden, M. (2012). The HILDA Survey: a case study in the design and development of a successful household panel study. Longitudinal and Life Course Studies, 3(3), 369381.

Wooden, M., \& Li, N. (2014). Panel conditioning and subjective well-being. Social Indicators Research, 117(1), 235-255.

Wooden, M., Warren, D., \& Drago, R. Working time mismatch and subjective well-being. British Journal of Industrial Relations, 47(1), 147-179 
Table 1. Incidence of smoking and normal weekly working hours: BHPS (waves 2 - 19) and HILDA Survey (waves 2 - 11)

\begin{tabular}{|c|c|c|c|c|c|c|c|c|c|c|c|c|}
\hline \multirow{4}{*}{ Country } & \multicolumn{2}{|c|}{ All } & \multirow{2}{*}{\multicolumn{2}{|c|}{$\begin{array}{c}\text { Men } \\
\text { BHPS waves } 2-19\end{array}$}} & \multirow{2}{*}{\multicolumn{2}{|c|}{ Women }} & \multirow{2}{*}{\multicolumn{2}{|c|}{ All }} & \multicolumn{2}{|c|}{ Men } & \multicolumn{2}{|c|}{ Women } \\
\hline & & & & & & & & & \multicolumn{2}{|c|}{ HILDA wave 2 - 11} & & \\
\hline & \multicolumn{2}{|c|}{ UK } & \multicolumn{2}{|c|}{ UK } & \multicolumn{2}{|c|}{ UK } & \multicolumn{2}{|c|}{ UK } & \multicolumn{2}{|c|}{$\mathrm{UK}$} & \multicolumn{2}{|c|}{$\mathrm{UK}$} \\
\hline & $\%$ & $\mathrm{~N}$ & $\%$ & $\mathrm{~N}$ & $\%$ & $\mathrm{~N}$ & $\%$ & $\mathrm{~N}$ & $\%$ & $\mathrm{~N}$ & $\%$ & $\mathrm{~N}$ \\
\hline \multicolumn{13}{|c|}{ Smoking } \\
\hline \multicolumn{13}{|c|}{ (Combined incidences across specified sample duration) } \\
\hline Smokers & 27.24 & 29,769 & 27.91 & 14,661 & 26.77 & 14,896 & 21.85 & 16,502 & 24.57 & 9,590 & 19.47 & 7,105 \\
\hline Non-smokers & 72.76 & 79,515 & 72.09 & 37,868 & 73.23 & 40,750 & 78.15 & 59,020 & 75.43 & 29,440 & 80.53 & 29,387 \\
\hline Smokers who stop smoking & 9.99 & 10,917 & 10.22 & 5,368 & 9.79 & 5,448 & 13.76 & 10,392 & 13.08 & 5,105 & 14.51 & 5,295 \\
\hline Non-smokers who start smoking & 2.66 & 2,907 & 2.83 & 1,487 & 2.53 & 1,408 & 3.06 & 2,311 & 5.51 & 2,151 & 2.7 & 985 \\
\hline $\begin{array}{l}\text { Mean number of cigarettes } \\
\text { smoked daily by smokers }\end{array}$ & 15.6 & 20,135 & 16.51 & 9,606 & 14.78 & 10,526 & 12.41 & 8,344 & 13.46 & 4,772 & 11.01 & 3,572 \\
\hline \multicolumn{13}{|l|}{ Weekly hours worked } \\
\hline$<20$ hours & 13.64 & 14,906 & 5.93 & 3,115 & 21.52 & 11,975 & 15.44 & 11,661 & 8.47 & 3,306 & 23.11 & 8,433 \\
\hline 20-34 hours & 15.47 & 16,906 & 5.53 & 2,905 & 25.56 & 14,223 & 16.79 & 12,680 & 8.65 & 3,376 & 25.75 & 9,397 \\
\hline $35-40$ hours & 33.23 & 36,315 & 33.8 & 17,755 & 32.52 & 18,096 & 33.2 & 25,073 & 34.63 & 13,516 & 31.63 & 11,542 \\
\hline 41-49 hours & 20.66 & 22,578 & 27.74 & 14,572 & 13.47 & 7,496 & 14.2 & 10,724 & 18.21 & 7,107 & 9.77 & 3,565 \\
\hline 50-59 hours & 10.47 & 11,442 & 16.11 & 8,462 & 4.75 & 2,643 & 12.28 & 9,274 & 17.72 & 6,916 & 6.29 & 2,295 \\
\hline $60+$ hours & 6.54 & 7,147 & 10.88 & 5,715 & 2.18 & 1,213 & 8.09 & 6,110 & 12.31 & 4,805 & 3.45 & 1,259 \\
\hline $\mathrm{N}$ (observations) & & 109,284 & & 52,529 & & 55,646 & & 75,522 & & 39,030 & & 36,492 \\
\hline $\mathrm{N}$ (individuals) & & 20,577 & & 10,191 & & 10,386 & & 14,479 & & 7,281 & & 7,198 \\
\hline
\end{tabular}

Estimates are unweighted.

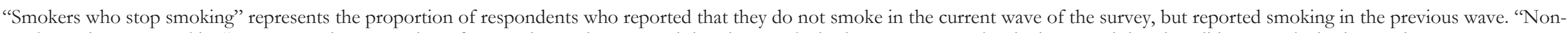

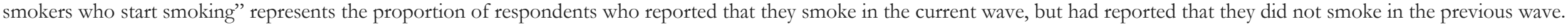

Equivalent statistics for each regression sample (below) are available in an on-line appendix via the journal website. 


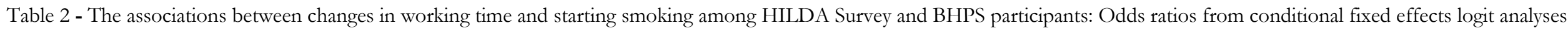

\begin{tabular}{|c|c|c|c|c|c|c|}
\hline & Start smoking (all) & Start smoking (all) & Start smoking (men) & Start smoking (men) & $\begin{array}{l}\text { Start smoking } \\
\text { (women) }\end{array}$ & $\begin{array}{l}\text { Start smoking } \\
\text { (women) }\end{array}$ \\
\hline & $\begin{array}{c}\text { BHPS } \\
\text { waves } 2 \text { - } 19\end{array}$ & $\begin{array}{c}\text { HILDA } \\
\text { waves } 2-11\end{array}$ & $\begin{array}{c}\text { BHPS } \\
\text { waves } 2-19\end{array}$ & $\begin{array}{c}\text { HILD } A \\
\text { waves } 2-11\end{array}$ & $\begin{array}{c}\text { BHPS } \\
\text { waves } 2-19\end{array}$ & $\begin{array}{c}\text { HILD } A \\
\text { waves } 2-11\end{array}$ \\
\hline Country & $U K$ & AUS & $U K$ & AUS & $U K$ & AUS \\
\hline $\begin{array}{l}\text { Weekly work hours } \\
\text { (Ref <35-40hr) }\end{array}$ & & & & & & \\
\hline$<20$ Hours & $\begin{array}{c}0.491 * * * \\
(0.352-0.686)\end{array}$ & $\begin{array}{c}0.480^{* * *} \\
(0.317-0.725)\end{array}$ & $\begin{array}{c}0.615 \\
(0.347-1.092)\end{array}$ & $\begin{array}{c}0.432^{*} \\
(0.210-0.891)\end{array}$ & $\begin{array}{c}0.404 * * * \\
(0.261-0.626)\end{array}$ & $\begin{array}{c}0.428^{* *} \\
(0.249-0.733)\end{array}$ \\
\hline 20-34 Hours & $\begin{array}{c}0.872 \\
(0.654-1.164)\end{array}$ & $\begin{array}{c}0.904 \\
(0.636-1.286)\end{array}$ & $\begin{array}{c}0.693 \\
(0.398-1.206)\end{array}$ & $\begin{array}{c}0.820 \\
(0.461-1.458)\end{array}$ & $\begin{array}{c}0.927 \\
(0.648-1.327)\end{array}$ & $\begin{array}{c}0.885 \\
(0.553-1.416)\end{array}$ \\
\hline 41-49 Hours & $\begin{array}{c}0.965 \\
(0.765-1.217)\end{array}$ & $\begin{array}{c}1.400 \\
(1.000-1.961)\end{array}$ & $\begin{array}{c}0.970 \\
(0.719-1.308)\end{array}$ & $\begin{array}{c}1.420 \\
(0.928-2.172)\end{array}$ & $\begin{array}{c}0.930 \\
(0.631-1.370)\end{array}$ & $\begin{array}{c}1.246 \\
(0.700-2.219)\end{array}$ \\
\hline 50-59 Hours & $\begin{array}{c}1.281 \\
(0.937-1.751)\end{array}$ & $\begin{array}{c}1.652^{*} \\
(1.113-2.452)\end{array}$ & $\begin{array}{c}1.192 \\
(0.816-1.739)\end{array}$ & $\begin{array}{c}1.617 \\
(0.985-2.654)\end{array}$ & $\begin{array}{c}1.650 \\
(0.903-3.014)\end{array}$ & $\begin{array}{c}1.531 \\
(0.750-3.125)\end{array}$ \\
\hline $60+$ Hours & $\begin{array}{c}1.685^{*} \\
(1.123-2.529) \\
\end{array}$ & $\begin{array}{c}2.016^{* *} \\
(1.242-3.274) \\
\end{array}$ & $\begin{array}{c}1.588 \\
(0.968-2.607) \\
\end{array}$ & $\begin{array}{c}1.801^{*} \\
(1.001-3.240) \\
\end{array}$ & $\begin{array}{c}1.752 \\
(0.826-3.718) \\
\end{array}$ & $\begin{array}{c}3.084 * \\
(1.203-7.907) \\
\end{array}$ \\
\hline Effective observations & 5,288 & 2,813 & 2,825 & 1,519 & 2,463 & 1,294 \\
\hline Effective individuals & 985 & 708 & 507 & 385 & 478 & 323 \\
\hline Hausman Test (chi²) & 299.30 & 166.56 & 103.93 & 115.35 & 307.83 & 64.13 \\
\hline Prob $>$ chi $^{2}$ (Hausman) & 0.0000 & 0.0000 & 0.0000 & 0.0000 & 0.0000 & 0.0000 \\
\hline
\end{tabular}

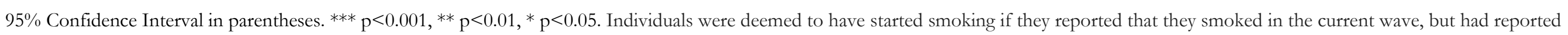
that they did not smoke in the previous wave of the survey.

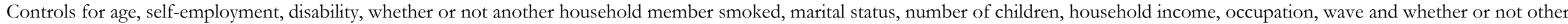
household members were present during the interview were included in the model but are not reported here. Full results are available from the authors on request. 


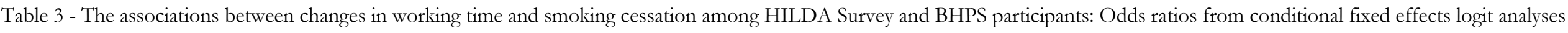

\begin{tabular}{|c|c|c|c|c|c|c|}
\hline & Stop smoking (all) & Stop smoking (all) & Stop smoking (men) & Stop smoking (men) & $\begin{array}{l}\text { Stop smoking } \\
\text { (women) }\end{array}$ & $\begin{array}{l}\text { Stop smoking } \\
\text { (women) }\end{array}$ \\
\hline & $\begin{array}{c}\text { BHPS } \\
\text { waves } 2 \text { - } 19\end{array}$ & $\begin{array}{c}\text { HILDA } \\
\text { waves } 2-11\end{array}$ & $\begin{array}{c}\text { BHPS } \\
\text { waves } 2 \text { - } 19\end{array}$ & $\begin{array}{c}\text { HILDA } \\
\text { waves } 2-11\end{array}$ & $\begin{array}{c}\text { BHPS } \\
\text { waves } 2 \text { - } 19\end{array}$ & $\begin{array}{c}\text { HILD A } \\
\text { waves } 2 \text { - } 11\end{array}$ \\
\hline Country & $U K$ & AUS & $U K$ & AUS & $U K$ & AUS \\
\hline $\begin{array}{l}\text { Weekly work hours } \\
\text { (Ref <35-40hr) }\end{array}$ & & & & & & \\
\hline$<20$ Hours & $\begin{array}{c}0.827 \\
(0.629-1.087)\end{array}$ & $\begin{array}{c}0.934 \\
(0.614-1.421)\end{array}$ & $\begin{array}{c}0.807 \\
(0.476-1.370)\end{array}$ & $\begin{array}{c}1.283 \\
(0.636-2.589)\end{array}$ & $\begin{array}{c}0.870 \\
(0.622-1.216)\end{array}$ & $\begin{array}{c}0.871 \\
(0.505-1.504)\end{array}$ \\
\hline 20-34 Hours & $\begin{array}{c}0.891 \\
(0.710-1.118)\end{array}$ & $\begin{array}{c}1.025 \\
(0.754-1.396)\end{array}$ & $\begin{array}{c}0.954 \\
(0.612-1.488)\end{array}$ & $\begin{array}{c}1.117 \\
(0.671-1.862)\end{array}$ & $\begin{array}{c}0.886 \\
(0.672-1.167)\end{array}$ & $\begin{array}{c}0.991 \\
(0.670-1.465)\end{array}$ \\
\hline 41-49 Hours & $\begin{array}{c}0.834 * \\
(0.707-0.984)\end{array}$ & $\begin{array}{c}0.771 \\
(0.590-1.006)\end{array}$ & $\begin{array}{c}0.945 \\
(0.763-1.169)\end{array}$ & $\begin{array}{c}0.695^{*} \\
(0.492-0.983)\end{array}$ & $\begin{array}{c}0.694^{* *} \\
(0.529-0.911)\end{array}$ & $\begin{array}{c}0.943 \\
(0.611-1.456)\end{array}$ \\
\hline 50-59 Hours & $\begin{array}{c}0.595^{* * *} \\
(0.471-0.752)\end{array}$ & $\begin{array}{c}0.707^{*} \\
(0.509-0.983)\end{array}$ & $\begin{array}{c}0.624 * * * \\
(0.472-0.824)\end{array}$ & $\begin{array}{c}0.659^{*} \\
(0.436-0.995)\end{array}$ & $\begin{array}{c}0.593^{*} \\
(0.373-0.942)\end{array}$ & $\begin{array}{c}0.787 \\
(0.437-1.417)\end{array}$ \\
\hline $60+$ Hours & $\begin{array}{c}0.465^{* * *} \\
(0.342-0.633)\end{array}$ & $\begin{array}{c}0.642^{*} \\
(0.419-0.985)\end{array}$ & $\begin{array}{c}0.513^{* * *} \\
(0.359-0.732)\end{array}$ & $\begin{array}{c}0.605 \\
(0.362-1.010)\end{array}$ & $\begin{array}{c}0.376^{* *} \\
(0.193-0.736)\end{array}$ & $\begin{array}{c}0.751 \\
(0.315-1.792)\end{array}$ \\
\hline Effective observations & 10,422 & 4,281 & 5,391 & 2,345 & 5,031 & 1,936 \\
\hline Effective individuals & 1,670 & 982 & 853 & 533 & 817 & 449 \\
\hline Hausman Test $\left(\mathrm{chi}^{2}\right)$ & 386.03 & 216.81 & 199.04 & 136.12 & 220.91 & 93.35 \\
\hline Prob $>\operatorname{chi}^{2}$ (Hausman) & 0.0000 & 0.0000 & 0.0000 & 0.0000 & 0.0000 & 0.0000 \\
\hline
\end{tabular}

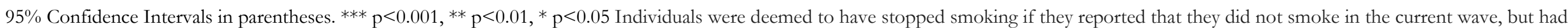
reported that they smoked in the previous wave of the survey.

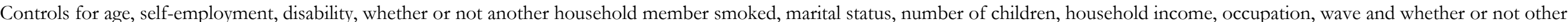
household members were present during the interview were included in the model but are not reported here. Full results are available from the authors on request. 


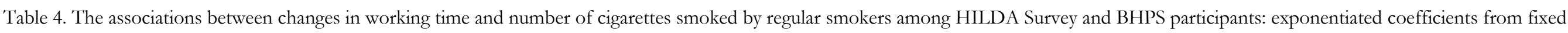
effects Poisson analyses

\begin{tabular}{|c|c|c|c|c|c|c|}
\hline & Daily cigarettes smoked & $\begin{array}{c}\text { Daily cigarettes } \\
\text { smoked }\end{array}$ & $\begin{array}{l}\text { Daily cigarettes } \\
\text { smoked (men) }\end{array}$ & $\begin{array}{l}\text { Daily cigarettes } \\
\text { smoked (men) }\end{array}$ & $\begin{array}{l}\text { Daily cigarettes } \\
\text { smoked (women) }\end{array}$ & $\begin{array}{l}\text { Daily cigarettes } \\
\text { smoked (women) }\end{array}$ \\
\hline & $\begin{array}{c}\text { BHPS } \\
\text { waves } 2 \text { - } 19\end{array}$ & $\begin{array}{c}\text { HILD } A \\
\text { waves } 3-11\end{array}$ & $\begin{array}{c}\text { BHPS } \\
\text { waves } 2 \text { - } 19\end{array}$ & $\begin{array}{c}\text { HILD A } \\
\text { waves } 3-11\end{array}$ & $\begin{array}{c}\text { BHPS } \\
\text { waves } 2-19\end{array}$ & $\begin{array}{c}\text { HILD } A \\
\text { waves } 3-11\end{array}$ \\
\hline Country & $U K$ & AUS & $U K$ & $A U S$ & $U K$ & AUS \\
\hline $\begin{array}{l}\text { Weekly work hours } \\
\text { (Ref <35-40hr) }\end{array}$ & & & & & & \\
\hline$<20$ Hours & $\begin{array}{c}1.012 \\
(0.991-1.033)\end{array}$ & $\begin{array}{c}0.968^{* * *} \\
(0.954-0.983)\end{array}$ & $\begin{array}{c}0.976 \\
(0.937-1.016)\end{array}$ & $\begin{array}{c}0.948^{* * *} \\
(0.924-0.973)\end{array}$ & $\begin{array}{c}1.270^{* *} \\
(1.020-1.520)\end{array}$ & $\begin{array}{c}0.989 \\
(0.970-1.008)\end{array}$ \\
\hline 20-34 Hours & $\begin{array}{c}0.998 \\
(0.981-1.014)\end{array}$ & $\begin{array}{c}0.985^{* * *} \\
(0.975-0.996)\end{array}$ & $\begin{array}{c}0.989 \\
(0.953-1.026)\end{array}$ & $\begin{array}{c}0.956^{* * *} \\
(0.941-0.971)\end{array}$ & $\begin{array}{c}1.04 \\
(0.984-1.230)\end{array}$ & $\begin{array}{c}1.160^{*} \\
(1.010-1.310)\end{array}$ \\
\hline 41-49 Hours & $\begin{array}{c}1.190 * * * \\
(1.070-1.320)\end{array}$ & $\begin{array}{c}1.200^{* * *} \\
(1.100-1.290)\end{array}$ & $\begin{array}{c}1.150^{* *} \\
(0.999-1.320)\end{array}$ & $\begin{array}{c}1.140^{*} \\
(1.030-1.250)\end{array}$ & $\begin{array}{c}1.240 * * \\
(1.040-1.440)\end{array}$ & $\begin{array}{c}1.420^{* * *} \\
(1.230-1.600)\end{array}$ \\
\hline 50-59 Hours & $\begin{array}{c}1.310^{* * * *} \\
(1.140-1.480)\end{array}$ & $\begin{array}{c}1.190 * * * \\
(1.090-1.300)\end{array}$ & $\begin{array}{c}1.270^{* * *} \\
(1.070-1.480)\end{array}$ & $\begin{array}{c}1.02 \\
(0.990-1.104)\end{array}$ & $\begin{array}{c}1.350^{* *} \\
(1.300-1.680)\end{array}$ & $\begin{array}{c}1.780^{* * *} \\
(1.540-1.810)\end{array}$ \\
\hline $60+$ Hours & $\begin{array}{c}1.610^{* * * *} \\
(1.390-1.840)\end{array}$ & $\begin{array}{c}1.06 \\
(0.993-1.200) \\
\end{array}$ & $\begin{array}{c}1.580^{* * *} \\
(1.320-1.840) \\
\end{array}$ & $\begin{array}{c}0.992 \\
(0.977-1.007) \\
\end{array}$ & $\begin{array}{c}1.57 * * \\
(1.009-1.608) \\
\end{array}$ & $\begin{array}{c}1.41 * \\
(1.090-1.730) \\
\end{array}$ \\
\hline Effective observations & 20,135 & 8,344 & 9,609 & 4,772 & 10,526 & 3,572 \\
\hline Effective individuals & 3,461 & 1,969 & 1,709 & 1,104 & 1,752 & 865 \\
\hline Hausman Test $\left(\right.$ chi² $\left.^{2}\right)$ & 838.08 & 108.62 & 417.50 & 62.75 & 393.53 & 86.58 \\
\hline Prob>chi ${ }^{2}$ (Hausman) & 0.0000 & 0.0000 & 0.0000 & 0.0000 & 0.0000 & 0.0000 \\
\hline
\end{tabular}

$95 \%$ Confidence Intervals in parentheses. ${ }^{* * *} \mathrm{p}<0.001,{ }^{* *} \mathrm{p}<0.01,{ }^{*} \mathrm{p}<0.05$.

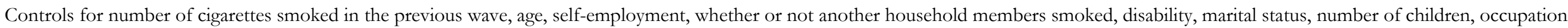

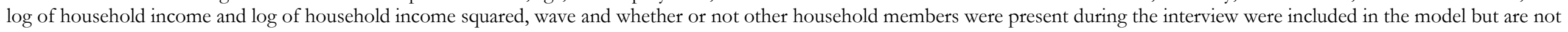
reported here. Full results are available from the authors on request. 
Table A1 Incidence of starting smoking and normal weekly working hours among Table 2 regression sample population: BHPS (waves 2 - 19) and HILDA Survey (waves 2 - 11)

\begin{tabular}{|c|c|c|c|c|c|c|c|c|c|c|c|c|}
\hline \multirow{3}{*}{ Country } & \multicolumn{2}{|c|}{ All } & \multicolumn{2}{|c|}{$\begin{array}{c}\text { Men } \\
\text { BHPS } \\
\text { waves 2-19 }\end{array}$} & \multicolumn{2}{|c|}{ Women } & \multicolumn{2}{|c|}{ All } & \multicolumn{2}{|c|}{$\begin{array}{c}\text { Men } \\
\text { HILDA } \\
\text { waves 2-11 }\end{array}$} & \multicolumn{2}{|c|}{ Women } \\
\hline & \multicolumn{2}{|c|}{ GB } & \multicolumn{2}{|c|}{ GB } & \multicolumn{2}{|c|}{ GB } & \multicolumn{2}{|c|}{ AUS } & \multicolumn{2}{|c|}{ AUS } & \multicolumn{2}{|c|}{ AUS } \\
\hline & $\%$ & $\mathrm{~N}$ & $\%$ & $\mathrm{~N}$ & $\%$ & $\mathrm{~N}$ & $\%$ & $\mathrm{~N}$ & $\%$ & $\mathrm{~N}$ & $\%$ & $\mathrm{~N}$ \\
\hline \multicolumn{13}{|c|}{ Smoking } \\
\hline \multicolumn{13}{|c|}{ (Combined incidences across specified sample duration) } \\
\hline Non-smokers who start smoking & 24.6 & 1,301 & 23.93 & 676 & 25.38 & 625 & 30.54 & 859 & 31.01 & 471 & 29.98 & 388 \\
\hline \multicolumn{13}{|l|}{ Weekly hours worked } \\
\hline$<20$ hours & 12.95 & 685 & 5.73 & 162 & 21.23 & 523 & 14.36 & 404 & 8.56 & 130 & 21.17 & 274 \\
\hline 20-34 hours & 14.07 & 744 & 5.56 & 157 & 23.83 & 587 & 17.6 & 495 & 9.28 & 141 & 27.36 & 354 \\
\hline $35-40$ hours & 32.36 & 1,711 & 32.92 & 930 & 31.71 & 781 & 33.49 & 942 & 35.88 & 545 & 30.68 & 397 \\
\hline 41-49 hours & 21.26 & 1,124 & 27.54 & 778 & 14.05 & 246 & 15.82 & 445 & 20.34 & 309 & 10.51 & 136 \\
\hline $50-59$ hours & 11.89 & 629 & 17.24 & 487 & 5.77 & 142 & 11.41 & 321 & 15.67 & 238 & 6.41 & 83 \\
\hline $60+$ hours & 7.47 & 395 & 11.01 & 311 & 3.41 & 84 & 7.32 & 206 & 10.27 & 156 & 3.86 & 50 \\
\hline $\mathrm{N}$ (observations) & 5288 & & 2825 & & 2463 & & 2813 & & 1519 & & 1294 & \\
\hline $\mathrm{N}$ (individuals) & 985 & & 507 & & 478 & & 708 & & 385 & & 323 & \\
\hline
\end{tabular}

Estimates are unweighted.

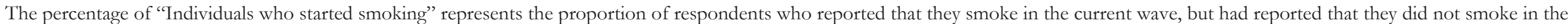

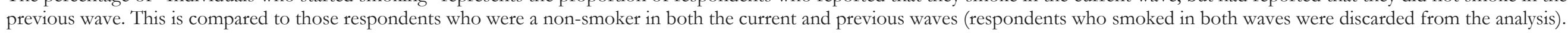


Table A2. Incidence of stopping smoking and normal weekly working hours among Table 3 regression sample population: BHPS (waves 2 - 19) and HILDA Survey (waves 2 - 11)

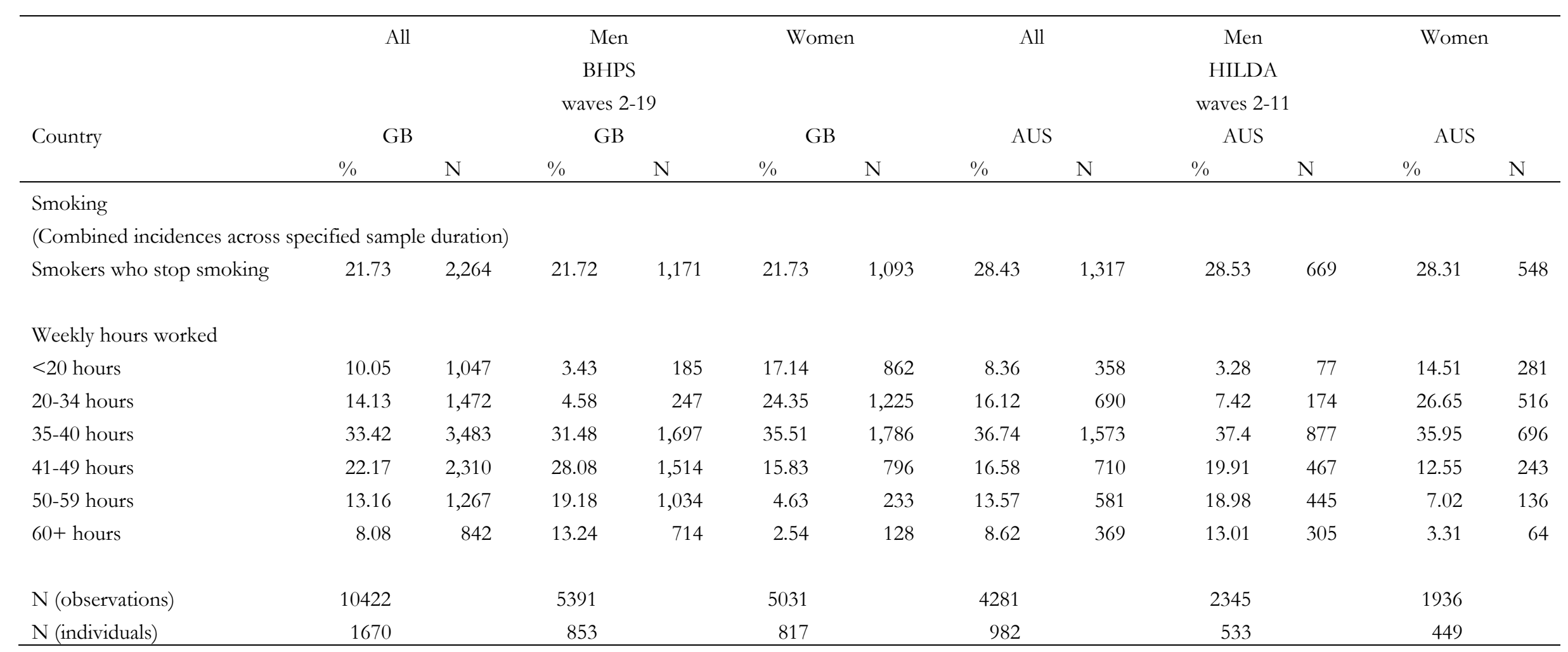

Estimates are unweighted.

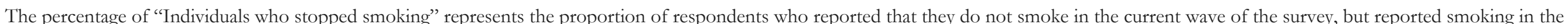

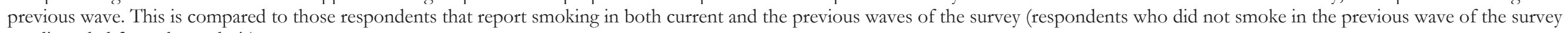
are discarded from the analysis). 
Table A3. The number of cigarettes smoked and normal weekly working hours among Table 4 regression sample population: BHPS (waves 2 - 19) and HILDA Survey (waves 3 - 11)

\begin{tabular}{|c|c|c|c|c|c|c|c|c|c|c|c|c|}
\hline \multirow{4}{*}{ Country } & \multicolumn{2}{|c|}{ All } & \multirow{2}{*}{\multicolumn{2}{|c|}{$\begin{array}{c}\text { Men } \\
\text { BHPS waves } 2-19\end{array}$}} & \multirow{2}{*}{\multicolumn{2}{|c|}{ Women }} & \multirow{2}{*}{\multicolumn{2}{|c|}{ All }} & \multicolumn{2}{|c|}{ Men } & \multicolumn{2}{|c|}{ Women } \\
\hline & & & & & & & & & \multicolumn{2}{|c|}{ HILDA waves 2 - 19} & & \\
\hline & \multicolumn{2}{|c|}{ GB } & \multicolumn{2}{|c|}{ GB } & \multicolumn{2}{|c|}{ GB } & \multicolumn{2}{|c|}{ AUS } & \multicolumn{2}{|c|}{ AUS } & \multicolumn{2}{|c|}{ AUS } \\
\hline & $\%$ & $\mathrm{~N}$ & $\%$ & $\mathrm{~N}$ & $\%$ & $\mathrm{~N}$ & $\%$ & $\mathrm{~N}$ & $\%$ & $\mathrm{~N}$ & $\%$ & $\mathrm{~N}$ \\
\hline \multicolumn{13}{|l|}{ Smoking } \\
\hline $\begin{array}{l}\text { Number of cigarettes smoked } \\
\text { (average daily consumption) - } \\
\text { Whole Sample }\end{array}$ & 15.04 & 109,284 & 15.89 & 52,529 & 14.38 & 55,646 & 11.74 & 75,522 & 12.83 & 39,030 & 9.15 & 36,492 \\
\hline $\begin{array}{l}\text { Number of cigarettes smoked } \\
\text { (average daily consumption) - } \\
\text { Regression Sample }\end{array}$ & 15.6 & 20,135 & 16.51 & 9,609 & 14.78 & 10,526 & 12.41 & 8,344 & 13.46 & 4,772 & 11.01 & 3,572 \\
\hline \multicolumn{13}{|l|}{ Weekly hours worked } \\
\hline$<20$ hours & 11.47 & 2,310 & 3.44 & 331 & 18.8 & 1,979 & 9.98 & 833 & 4.44 & 212 & 17.39 & 621 \\
\hline 20-34 hours & 15.36 & 3,092 & 3.93 & 378 & 25.79 & 2,714 & 17.38 & 1,450 & 8.8 & 420 & 28.84 & 1,030 \\
\hline $35-40$ hours & 32.94 & 6,633 & 33.16 & 3,186 & 32.75 & 3,447 & 36.51 & 3,046 & 38.29 & 1,827 & 34.13 & 1,219 \\
\hline 41-49 hours & 23.49 & 4,729 & 31.13 & 2,991 & 16.51 & 1,738 & 15.22 & 1,270 & 18.42 & 879 & 10.95 & 391 \\
\hline 50-59 hours & 10.84 & 2,182 & 17.91 & 1,721 & 4.38 & 461 & 12.63 & 1,054 & 17.62 & 841 & 5.96 & 213 \\
\hline $60+$ hours & 5.9 & 1,188 & 10.43 & 1,002 & 1.77 & 186 & 8.28 & 691 & 12.43 & 593 & 2.74 & 98 \\
\hline N (observations) & 20135 & & 9609 & & 10526 & & 8344 & & 4772 & & 3572 & \\
\hline $\mathrm{N}$ (individuals) & 3461 & & 1709 & & 1752 & & 1969 & & 1104 & & 865 & \\
\hline
\end{tabular}

Estimates are unweighted. 